\title{
Deposition of DLC/oxynitriding Films onto JIS SKD11 Steel by Bipolar-pulsed PECVD
}

\author{
Shih-Hsien CHANG, ${ }^{1) *}$ Chun-Cheng YU, ${ }^{1)}$ Kuo-Tsung HUANG ${ }^{2)}$ and Chung-Ming LIU ${ }^{31}$ \\ 1) Department of Materials and Mineral Resources Engineering, National Taipei University of Technology, Taipei 10608, \\ Taiwan, ROC. $\quad$ 2) Department of Auto-Mechanics, National Kangshan Agricultural Industrial Senior High School, Kaohsiung \\ 82049, Taiwan, ROC. $\quad 3)$ Department of Chemical and Material Engineering, Lunghwa University of Science and Tech- \\ nology, Taoyuan City 33306, Taiwan, ROC.
}

(Received on June 15, 2015; accepted on August 24, 2015)

\begin{abstract}
In this study, diamond-like carbon (DLC) films are coated by bipolar-pulsed PECVD onto oxynitridingtreated JIS SKD11 steel. In order to evaluate the properties of the DLC/oxynitriding films on SKD11 steel, Raman spectroscopy analysis, wear tests, adhesion tests, hardness tests and corrosion resistance inspections are performed. The experimental results show that the DLC/oxynitride duplex layers possess ideal wear and corrosion resistance when DLC films are deposited by unbalanced bipolar-pulsed voltage, with a coating time of $90 \mathrm{~min}$ and duty cycles maintained at $15 \%$. The highest surface hardness $\left(\mathrm{Hv}_{0.025}\right.$ 2 830.7) and lowest wear volume loss (when the load of $2 \mathrm{~N}$ and sliding speed of $0.05 \mathrm{~m} \cdot \mathrm{s}^{-1}$ is $4.07 \times$ $10^{-3} \mathrm{~mm}^{3}$ and the load of $5 \mathrm{~N}$ and sliding speed of $0.25 \mathrm{~m} \cdot \mathrm{s}^{-1}$ is $5.83 \times 10^{-3} \mathrm{~mm}^{3}$, respectively) are obtained. In addition, the optimal DLC/oxynitride films also possess the lowest corrosion current $\left(\mathrm{I}_{\text {corr }}=\right.$ $\left.2.66 \times 10^{-6} \mathrm{~A} \cdot \mathrm{cm}^{-2}\right)$ and highest polarization resistance $\left(R_{p}=1.57 \times 10^{4} \Omega \cdot \mathrm{cm}^{2}\right)$ in $3.5 \mathrm{wt} \% \mathrm{NaCl}$ solutions.
\end{abstract}

KEY WORDS: DLC; bipolar-pulsed PECVD; oxynitriding; SKD11; wear; corrosion resistance.

\section{Introduction}

Traditionally, JIS SKD11 tool steel is corresponding to the AISI D2. Since this material possesses high hardness and excellent wear resistance, it is usually used as a mold material and cutting tools. ${ }^{1,2)}$ In order to improve the tool life, many studies have focused on surface treatment as a method of protecting the internal material. ${ }^{2)}$

Nitriding is a thermo-chemical process with nitrogen diffusion, which leads to increase the surface hardness of the treated steels. It reveals an effective improvement of thermal fatigue characteristics due to the effects of compressive stress and the hardened surface. ${ }^{3)}$ In addition, oxynitriding processes use air or steam at the end of the nitriding stage; used as an oxidizing medium, they are an integral part of the treatment. Generally, the oxynitriding process can form several kinds of nitride $\left(\mathrm{Fe}_{2} \mathrm{~N}, \mathrm{Fe}_{3} \mathrm{~N}\right.$ and $\left.\mathrm{Fe}_{4} \mathrm{~N}\right)$ and oxides $\left(\mathrm{Fe}_{2} \mathrm{O}_{3}\right.$ and $\left.\mathrm{Fe}_{3} \mathrm{O}_{4}\right)$. Especially, the $\mathrm{Fe}_{3} \mathrm{O}_{4}$ layer of oxidation treatment can effectively protect and improve the erosion and corrosion resistance of steels. ${ }^{4,5)}$

Diamond-like carbon (DLC) films are metastable amorphous carbon ( $\mathrm{sp}^{3}$ and $\mathrm{sp}^{2}$ bonds) materials with superior tribological characteristics. $\left.{ }^{6}\right)$ The high hardness, low friction coefficient and chemical resistance of the DLC films make them good candidates as protective coatings for metal, steels and optical or electronic components. ${ }^{7)}$ Recently, direct cur-

* Corresponding author: E-mail: changsh@ntut.edu.tw

DOI: http://dx.doi.org/10.2355/isijinternational.ISIJINT-2015-350 rent pulsed (DC-pulsed) plasma-enhanced chemical vapor deposition (PECVD) is one of the most promising methods for surface modification of tool steels used in various industries. ${ }^{8-10)}$ This technique enables the uniform coating of complex-shaped parts like forming tools or the die casting components because of the higher operating pressure as compared to PVD, and due to plasma activation of the gas phase, lowers the deposition temperature significantly as compared to conventional thermal CVD. Other studies also indicated that the DLC films problem in sustaining stable plasma conditions during the deposition of insulating films could be solved by using bipolar-pulsed plasma sources. Meanwhile, the adhesion and properties of DLC film can be improved effectively. ${ }^{11,12)}$ Since the bipolar-pulsed PECVD is believed to be less problematic with respect to electrical charging and arcing than unipolar-pulsed technology. ${ }^{9}$ )

JIS SKD11 steel is a widely used cold work tool steel due to its high wear resistance and appropriate toughness. The $\mathrm{Fe}_{3} \mathrm{O}_{4}$ layer of an oxynitriding treatment can effectively protect and improve the erosion and corrosion resistance of steels. In this study, the DLC/oxynitriding duplex treatment utilized a bipolar-pulsed PECVD process to coat the oxynitriding-treated SKD11 steel in order to study the characteristics of DLC films and so increase tool life.

\section{Experimental Procedures}

In the research, JIS SKD11 steel was chosen as the substrate material which was to undergo a homogeneous heat 
treatment: nitrogen was quenched at $1030^{\circ} \mathrm{C}$ and tempered at $520^{\circ} \mathrm{C}$ for $3 \mathrm{~h}$; this process was repeated 3 times to reach a hardness of $60 \pm 1 \mathrm{HRC}$. The steel was then subjected to various surface treatments, including oxynitriding and a DLC coating with oxynitriding. A typical microstructure of JIS SKD11 steel was obtained through commercial heat treatment, comprising the structure of tempered martensite and various metallic carbides. The chemical compositions (mass.\%) of SKD11 steel are as follows: $1.55 \% \mathrm{C}, 0.3 \% \mathrm{Si}$, $0.4 \% \mathrm{Mn}, \leqq 0.025 \% \mathrm{P}, \leqq 0.010 \% \mathrm{~S}, 11.8 \% \mathrm{Cr}, 0.8 \% \mathrm{Mo}$, $0.8 \% \mathrm{~V}$ and a balance of Fe, respectively. Meanwhile, the oxynitriding-treated specimens of SKD11 steel were nitriding treated for $8 \mathrm{~h}$ at $480^{\circ} \mathrm{C}$ and oxidized via steam for 30 $\min$ at $480^{\circ} \mathrm{C}$.

The DLC/oxynitriding duplex treatments, in which oxynitriding was treated the same as the abovementioned process, involved depositing a DLC coating onto oxynitridingtreated SKD11 steels. The DLC coating utilized bipolarpulsed PECVD technology. In this work, the 5\% duty cycle of the bipolar-pulsed PECVD meant that the plasma deposition time was only $5 \mu$ s during $100 \mu$ s. Simultaneously, the $\mathrm{T}_{\text {on }}{ }^{+}$(or $\mathrm{T}_{\text {on }}{ }^{-}$) of the positive-pulsed duty cycle was kept at $10 \mu \mathrm{s}$ and the $\mathrm{T}_{\text {off }}{ }^{+}$(or $\mathrm{T}_{\text {off }}{ }^{-}$) was $40 \mu \mathrm{s}$. In order to study the effects of different duty cycles of the bipolarpulsed PECVD process, the positive-pulsed duty cycle was maintained at $10 \%$ and the negative-pulsed duty cycles were $5 \%, 10 \%, 15 \%, 20 \%$ and $25 \%$, respectively. The different duty cycles of the bipolar-pulsed PECVD process are designated as 5\%,10\%,15\%,20\% and 25\%, hereafter. Simultaneously, we also measured the power density of energy of $5 \%, 10 \%, 15 \%, 20 \%$ and $25 \%$, which was equal to the $265 \pm 5 \mathrm{mWcm}^{-2}, 300 \pm 5 \mathrm{mWcm}^{-2}, 400 \pm 5 \mathrm{mWcm}^{-2}$, $500 \pm 5 \mathrm{mWcm}^{-2}$ and $610 \pm 5 \mathrm{mWcm}^{-2}$, respectively. Furthermore, the coating time of the bipolar-pulsed PECVD was maintained at $90 \mathrm{~min}$; the frequency was $10 \mathrm{kHz}$; the negative and positive voltage of unbalanced bipolar-pulsed was kept at -1.5 and $0.3 \mathrm{kV}$, respectively. In addition, $\mathrm{CH}_{4}$ gas $(5 \mathrm{sccm})$ was added at less than $1.33 \mathrm{~Pa}$ and continued for $90 \mathrm{~min}$, and followed by depositing of the DLC films.

In order to evaluate the properties of DLC films for DLC/ oxynitriding treated SKD11 steel by different duty cycles of the bipolar-pulsed PECVD, the Raman spectroscopy analysis (MOF-iHR550), wear test (POD-FM406), roughness test (ET4000A), indentation test (Indentec-8150LK), ${ }^{13)}$ scratch test (ASTM C1624-5, JLST022 Scratch Tester J \& L Tech. Co., Korea) and SEM (Hitachi-S4700) microstructure inspections were performed. The wear resistance of the specimens was evaluated in a ball-on-disk test (ASTM G99). The wear test parameters were as follows: the specimen size was $\varnothing 36 \times \mathrm{D} 5 \mathrm{~mm}$, diameter of WC ball (HRA $90 \pm 1$ ) was $6 \mathrm{~mm}$, disk rotation was $200 \mathrm{rpm}$ and total rotation was 10000 revolutions, axial load was $2 \mathrm{~N}$ and sliding speed was $0.05 \mathrm{~m} \cdot \mathrm{s}^{-1}$, another wear parameter was load of $5 \mathrm{~N}$ and sliding speed of $0.25 \mathrm{~m} \cdot \mathrm{s}^{-1}$.

Furthermore, corrosion potential analysis uses three electrodes method and follows by ASTM G59-97: the reference electrode is a saturated of silver-silver chloride electrode, auxiliary electrode uses a platinum electrode, and the working electrode is connected to the test specimens [4]. The contact area of the specimen was $2.01 \mathrm{~cm}^{2}$. The corrosive solvent used $3.5 \mathrm{wt} \% \% \mathrm{NaCl}$ was maintained at room tem- perature. A scanning speed of $0.01 \mathrm{Vs}^{-1}$, initial potential of $-1.5 \mathrm{~V}$, and the final potential of $1.0 \mathrm{~V}$ were controlled. The polarization curve was obtained by Corr-View software to analyze and compare the corrosion potential $\left(\mathrm{E}_{\mathrm{corr}}\right)$, corrosion current $\left(\mathrm{I}_{\text {corr }}\right)$ and polarization resistance $\left(\mathrm{R}_{\mathrm{p}}\right)$ of DLC/ oxynitriding treated SKD11 specimens.

\section{Results and Discussion}

Figure 1 shows the XRD patterns and surface hardness of the oxynitriding-treated SKD11 steel. The primary phases and structures of the oxynitride layer were $\mathrm{Fe}_{3} \mathrm{O}_{4}$, $\mathrm{Fe}_{3} \mathrm{~N}$ ( $\varepsilon$ phase) and $\mathrm{Fe}_{4} \mathrm{~N}$ ( $\gamma^{\prime}$ phase), as shown in Fig. 1(a), while $\alpha-\mathrm{Fe}$ and $\mathrm{Cr}$ were the main matrix elements for the SKD11 steel, which also appeared in the XRD patterns. This result proved that the SKD11 steel, which was successfully nitride-treated at $480^{\circ} \mathrm{C}$ for $8 \mathrm{~h}$ and oxide-treated at $480^{\circ} \mathrm{C}$ for $30 \mathrm{~min}$, possessed a well-oxidized layer and stable crystal structures.

The surface hardness was measured at an applied load of $0.49 \mathrm{~N}$ (approximately equal to $50 \mathrm{~g}$, which we express by $\mathrm{Hv}_{0.05}$ in this study and tested at least three times) along the cross section of the test pieces through the micro-hardness tester (VMT-XT). Consequently, the depth profile of the microhardness of oxynitriding-treated SKD11 steel was obtained as shown in Fig. 1(b). Because the specimen's surface possessed a higher concentration of oxide and nitro-
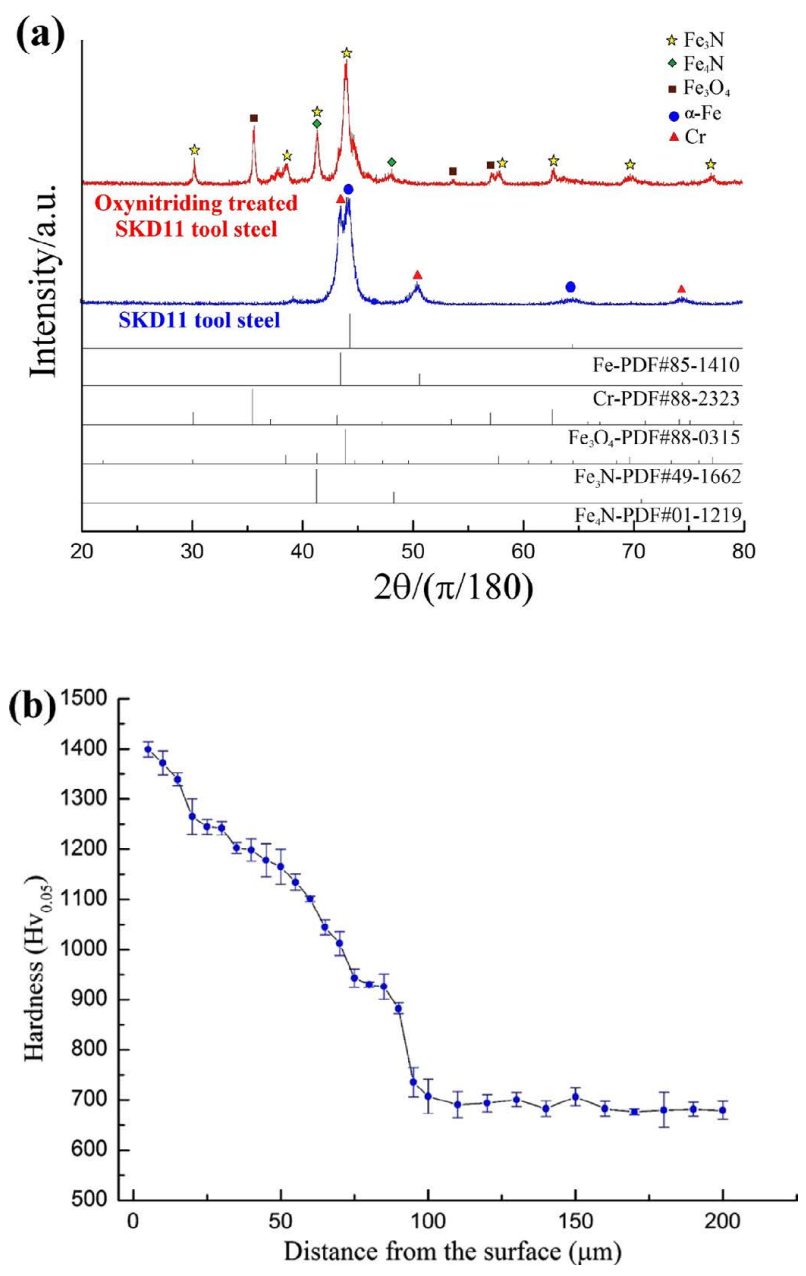

Fig. 1. XRD patterns and hardness test results of the oxynitriding treated SKD11 tool steel. (Online version in color.) 
gen ions, a significant hardening effect of the atomic lattice was easily caused. Thus, the surface hardness of the oxynitriding-treated specimen was elevated to a high of $\mathrm{Hv}_{0.05}$ 1 399.3. However, with an increased diffusion depth, the oxide and nitrogen concentrations were obviously reduced, which led to a decrease in hardness. The hardness reverted to the original hardness of the substrate (about $\mathrm{Hv}_{0.05}$ 710.4) after a depth of $100 \mu \mathrm{m}$. In the present study, the depth of the surface-hardened oxynitriding layers (mainly $\mathrm{Fe}_{3} \mathrm{~N}$ and $\mathrm{Fe}_{4} \mathrm{~N}$ structures) was about $20 \mu \mathrm{m}$ and the diffusion layer was less than $95 \mu \mathrm{m}$ after the oxynitriding treatments. Significantly, the stable oxide $\left(\mathrm{Fe}_{3} \mathrm{O}_{4}\right)$ and nitriding layers $\left(\mathrm{Fe}_{3} \mathrm{~N}\right.$ and $\left.\mathrm{Fe}_{4} \mathrm{~N}\right)$ were successfully formed on the surface of SKD11 steel by the oxynitriding treatments, which led to an increase in the surface hardness of the steel.

Previous literature has indicated that an important potential benefit is that carbon clusters play a significant role in the growth of DLC films or crystalline diamond. ${ }^{14)}$ Gaussian function dismantling and synthesis were used to calculate the results of the integration area ratio $\left(\mathrm{I}_{\mathrm{D}} / \mathrm{I}_{\mathrm{G}}\right)$ and the offset of the G-peak by the different duty cycles of the bipolarpulsed PECVD. ${ }^{3)}$ Figure 2(a) shows that a bulge in the Raman band occurred at $1550 \mathrm{~cm}^{-1}$. The Raman spectra of the different duty cycles displayed the overlaps; therefore, it was necessary to further analyze the synthesized peak decomposition to obtain the value of $\mathrm{I}_{\mathrm{D}} / \mathrm{I}_{\mathrm{G}}$ and the offset of the G-peak position. Figure 2 (b) shows that the $5 \%$ duty cycles possessed the highest value of $\mathrm{I}_{\mathrm{D}} / \mathrm{I}_{\mathrm{G}}(0.65)$ and the smallest offset amount of G-peak (1 544.5). Upon increas-
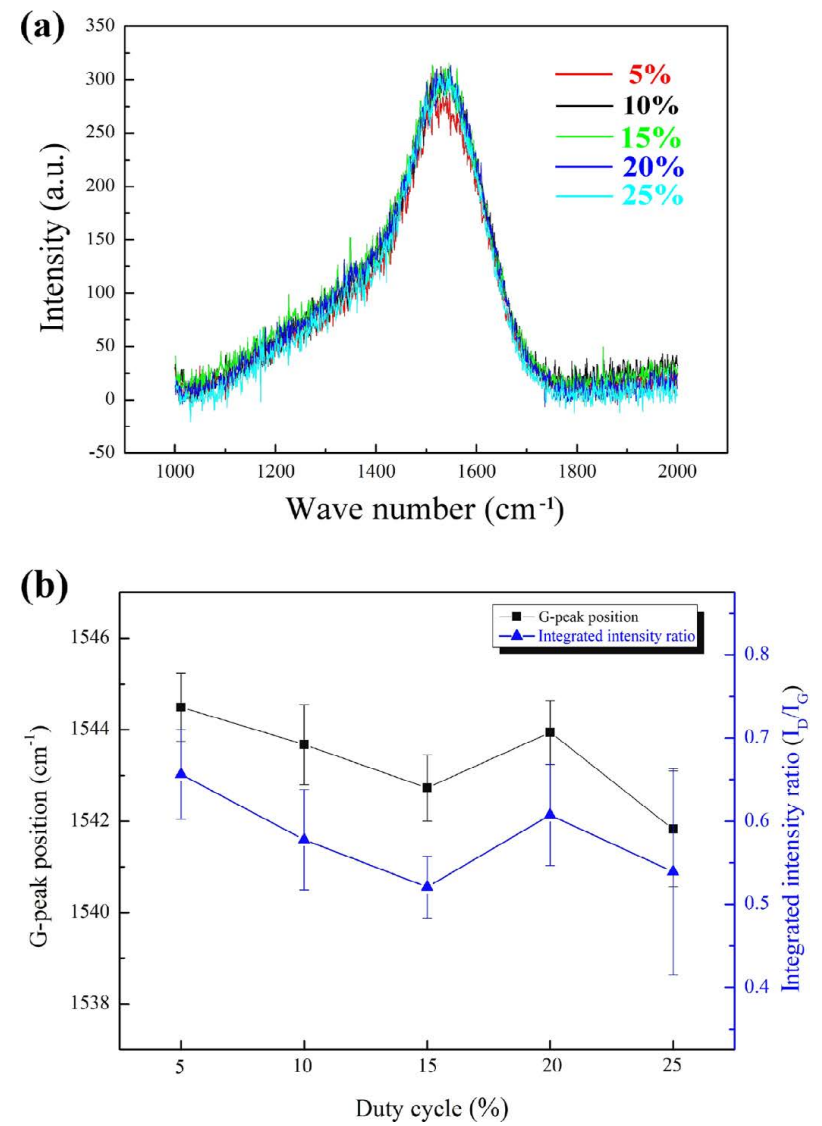

Fig. 2. Comparison of the (a) original Raman spectrum, and (b) $\mathrm{I}_{\mathrm{D}} / \mathrm{I}_{\mathrm{G}}$ and $\mathrm{G}$-peak of Raman analysis by different duty cycles of bipolar-pulsed PECVD. (Online version in color.) ing the duty cycles of the bipolar-pulsed PECVD, both the value of $\mathrm{I}_{\mathrm{D}} / \mathrm{I}_{\mathrm{G}}$ and the position of the G-peak obviously declined, and then rapidly rose and declined, respectively. Consequently, the $15 \%$ duty cycle specimen possessed the lowest value of $\mathrm{I}_{\mathrm{D}} / \mathrm{I}_{\mathrm{G}}(0.52)$ and the relatively greater offset amount of G-peak (1 542.7).

Previous literature has indicated ${ }^{9)}$ that the difference in power matching is reflected in the response time to the temporarily varying plasma states. Our previous studies ${ }^{3)}$ also showed that the $5 \%$ and $10 \%$ duty cycles had more off-time and so were sufficient to release the charge accumulation; thus, their power density of energy and gas dissociation rate were relatively lower, which resulted in the poor properties of the DLC films. By increasing the duty cycle $(5 \% \rightarrow$ $10 \%$ ) of the DC-pulsed PECVD process, the power density of the specimen was obviously increased $(265 \pm 5 \rightarrow 300 \pm 5$ $\mathrm{mWcm}^{-2}$ ). Furthermore, the $15 \%$ duty cycles generated the suitable power density of $400 \pm 5 \mathrm{mWcm}^{-2}$. Conversely, the power density of the $20 \%$ and $25 \%$ duty cycles was higher (over $500 \pm 5 \mathrm{mWcm}^{-2}$ ). The higher ion energy of the plasma bombardment easily caused the specimen's surface energy to increase and, thus, unstable structures were generated. This led to a maximum likelihood that the $\mathrm{sp}^{3}$ structure of the DLC films transformed to $\mathrm{sp}^{2}$ and, further, it affected the film's characteristics so that the DLC films gradually approached graphitization. Therefore, the 20\% and $25 \%$ duty cycles possessed a relatively higher value of $\mathrm{I}_{\mathrm{D}} / \mathrm{I}_{\mathrm{G}}$ (compared to the $15 \%$ duty cycle).

The result can also be compared with our previous study of unipolar-pulsed PECVD. The $15 \%$ duty cycle of the bipolar-pulsed PECVD $\left(\mathrm{I}_{\mathrm{D}} / \mathrm{I}_{\mathrm{G}}\right.$ of 0.52 and $\mathrm{G}$-peak offset of $1542.7 \mathrm{~cm}^{-1}$ ) resulted in better DLC films, as compared with the optimal unipolar-pulsed PECVD $\left(\mathrm{I}_{\mathrm{D}} / \mathrm{I}_{\mathrm{G}}\right.$ of 0.63 and G-peak offset of $1540.4 \mathrm{~cm}^{-1}$ ). Although the specimen treated with bipolar-pulsed PECVD showed a lower value of $\mathrm{I}_{\mathrm{D}} / \mathrm{I}_{\mathrm{G}}$, the specimen did not show a higher G-peak offset. The results suggest that the positive-pulsed treatment was more effective in slowing down the particle impact. Thus, the DLC films produced less compressive stress during deposition and had more carbon atoms to form the $\mathrm{sp}^{3}$ and bond with other carbon atoms with the bipolar-pulsed PECVD. In addition, due to the increase in the $\mathrm{sp}^{3}$ bonds, the $\mathrm{sp}^{2}$ bonds reduced to a critical value, which mitigated the G-peak offset. This finding was consistent with our previous study.

In the research, the scratch test gradually increased the load from 0 to $50 \mathrm{~N}$, and the total traveling distance was $5 \mathrm{~mm}$. All specimens showed no significant rupture of the DLC films after the scratch tests. Even at a maximum load of $50 \mathrm{~N}$, at the end of the scratch test a good bonding strength of the DLC films was still retained. Figure 3 shows the variations of the friction coefficient for the scratch test for the different duty cycles of bipolar-pulsed PECVD. Clearly, the friction coefficients of the different duty cycles all displayed a similar gentle level (from 0.5 to $2.0 \mathrm{~mm}$ of the scratch distance). However, the friction coefficient of the $15 \%$ duty cycle was a relatively smooth level after the 2.0 $\mathrm{mm}$ scratch distance. This result showed that the specimens of the $15 \%$ duty cycles had a relatively better ability to resist rupture and also possessed the more stable adhesion strength of DLC films. However, the optimum adhesion strength of DLC films needed to be confirmed and analyzed. 
Figure 4 shows the SEM images of the loading impact test (Rockwell $\mathrm{C}$ scale indentation) by different duty cycles of the bipolar-pulsed PECVD process. In addition to the radial cracks of the substrate, there was no other significant

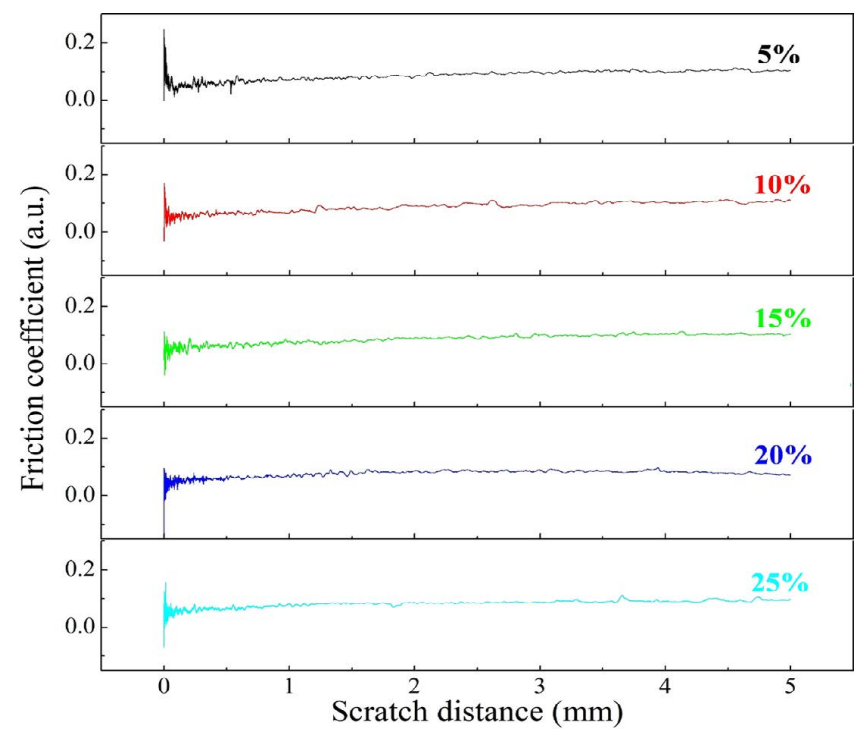

Fig. 3. Comparison of the variation of the friction coefficient of scratch test by the different duty cycles of bipolar-pulsed PECVD. (Online version in color.)
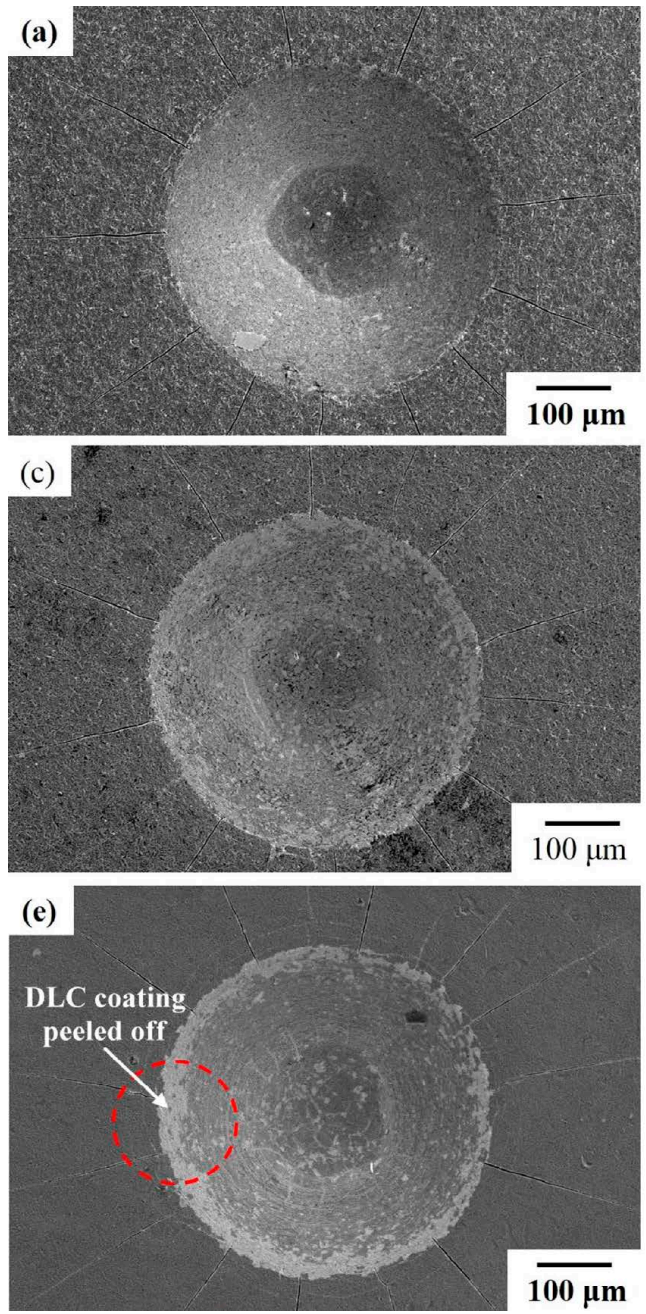

peeling-off phenomenon, as seen in Figs. 4(a)-4(d). However, the DLC coatings of the $25 \%$ duty cycle had a more obviously peeled-off appearance, as shown in Fig. 4(e). However, the radial cracks did not result from fractures of the DLC films, but were caused by the compressive stress on the specimen's surface from the oxynitriding process. Typically, the adhesion strength of DLC films on steel is poor, and adhesion-enhancing materials have been used directly as intermediate layers. ${ }^{15)}$ In this study, the oxynitriding process used pre-treated SKD11 steel as an intermediate layer. As a result, the nitrogen and oxide atoms entered the interstices of the lattice via atomic diffusion, and easily resulted in lattice deformation and surface hardening. The $25 \%$ duty cycle treatment involved a longer plasma bombardment, which resulted in a larger internal residual stress and more uneven $\mathrm{sp}^{3}$ and $\mathrm{sp}^{2}$ structures. Therefore, the adhesion strength of the 5-20\% duty cycle-treated DLC films belonged to the HF 1-2 grade; but the $25 \%$ duty cycle was HF 3 grade. ${ }^{12,15)}$

DLC films are metastable amorphous carbon materials with $\mathrm{sp}^{3}$ and $\mathrm{sp}^{2}$ bonds. Of all the surface treatment materials, DLC film has received the most attention because of its superior tribological characteristics correlated to the fraction of $\mathrm{sp}^{3}$ bonds in the films, such as its low friction coefficient and high wear resistance. $\left.{ }^{6}\right)$ Generally, the volume loss of the wear tests allows the wear rate of the material to be
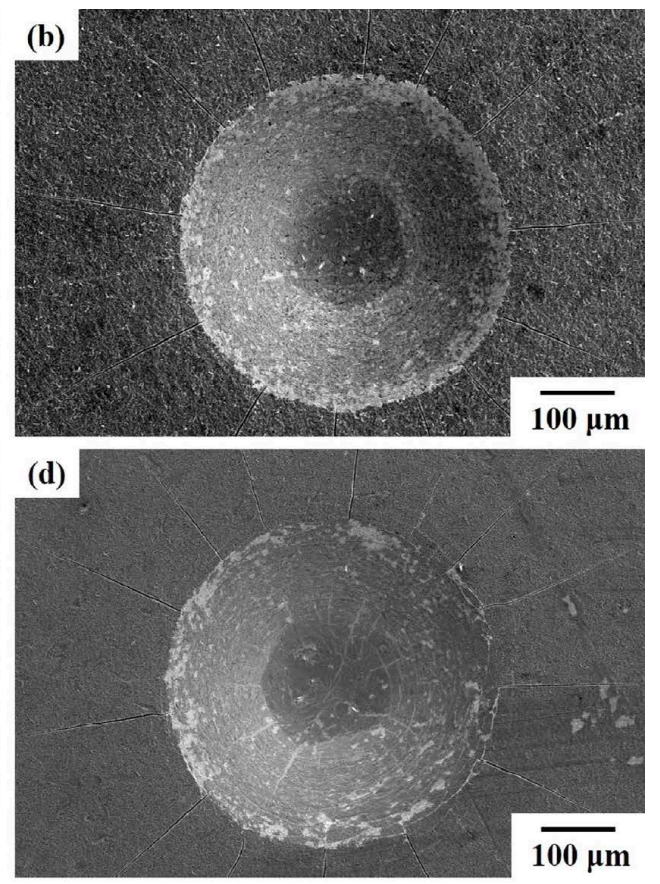

Fig. 4. SEM images of the loading impact test by the various duty cycles of bipolar-pulsed PECVD: (a) 5\%, (b) $10 \%$, (c) $15 \%$, (d) $20 \%$, and (e) $25 \%$. (Online version in color.) 
calculated. Figure 5 reveals the wear volume of the different duty cycles of the bipolar-pulsed PECVD. Figure 5(a) shows that the wear volume obviously decreased and then increased as the duty cycles increased. The highest value of wear volume $\left(6.12 \times 10^{-3} \mathrm{~mm}^{3}\right)$ appeared in the $5 \%$ duty cycles because the properties of the DLC films exhibited an unstable structure. In addition, the lowest wear volume $\left(4.07 \times 10^{-3} \mathrm{~mm}^{3}\right)$ appeared in the $15 \%$ duty cycles. Thus, it is possibly to say that the $15 \%$ duty cycles possessed the optimal wear resistance during the lower loads $(2 \mathrm{~N})$ and sliding speeds $\left(0.05 \mathrm{~ms}^{-1}\right)$.

Increasing the axial loads $(2 \rightarrow 5 \mathrm{~N})$ and sliding speeds $\left(0.05 \rightarrow 0.25 \mathrm{~ms}^{-1}\right)$ of the wear test obviously increased the wear volume of all the different duty cycles. Figure 5(b) shows that the wear volumes revealed a decreasing and then an increasing trend $\left(8.26 \times 10^{-3} \rightarrow 6.65 \times 10^{-3} \rightarrow\right.$ $\left.5.83 \times 10^{-3} \rightarrow 7.08 \times 10^{-3} \rightarrow 9.71 \times 10^{-3} \mathrm{~mm}^{3}\right)$ as the duty cycles of the bipolar-pulsed PECVD increased $(5 \rightarrow$ $10 \rightarrow 15 \rightarrow 20 \rightarrow 25 \%$ ). The lowest wear volume also appeared in the $15 \%$ duty cycle at higher loads and fast sliding speeds. From the above discussion and results, it was confirmed that the $15 \%$ duty cycles of the bipolar-pulsed PECVD possessed the optimal wear resistance.

Figure 6 shows the SEM surface morphology of the wear test under a load of $2 \mathrm{~N}$ and a sliding speed of $0.05 \mathrm{~m} \cdot \mathrm{s}^{-1}$ for the different duty cycles of the bipolar-pulsed PECVD.
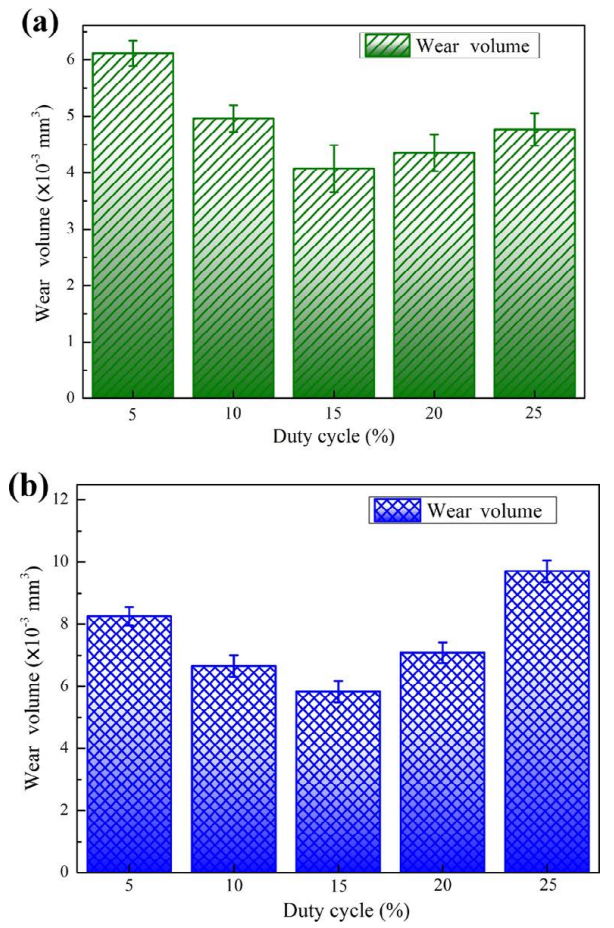

Fig. 5. Comparison of the wear volume loss of various wear tests by the different duty cycles of bipolar-pulsed PECVD: (a) load $2 \mathrm{~N}$ and sliding speed $0.05 \mathrm{~m} \cdot \mathrm{s}^{-1}$, and (b) load $5 \mathrm{~N}$ and sliding speed $0.25 \mathrm{~m} \cdot \mathrm{s}^{-1}$. (Online version in color.)
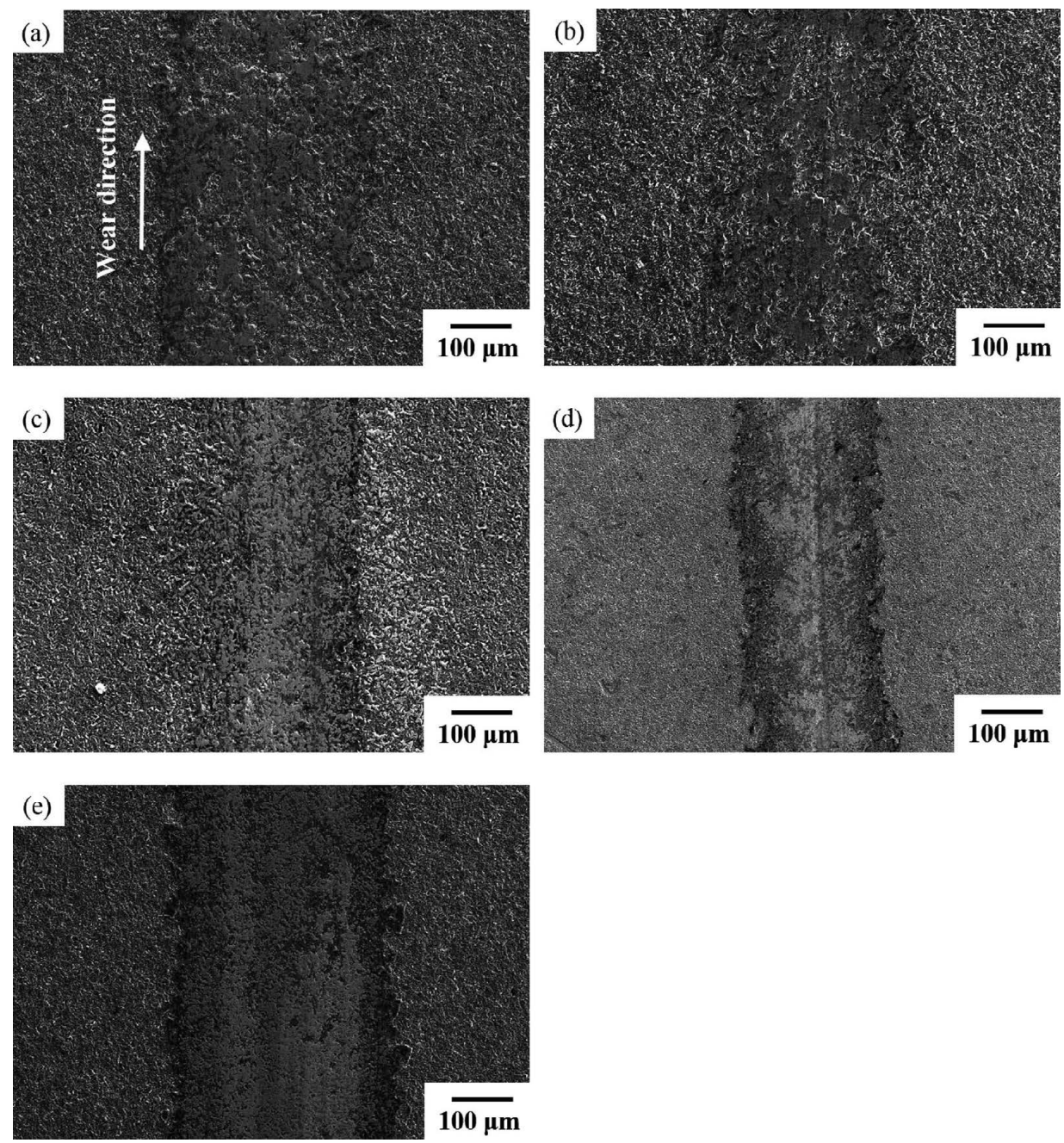

Fig. 6. Surface morphology observations of wear test (sliding speed $0.05 \mathrm{~m} \cdot \mathrm{s}^{-1}$ and load $2 \mathrm{~N}$ ) by the different duty cycles of bipolar-pulsed PECVD: (a) $5 \%$, (b) $10 \%$, (c) $15 \%$, (d) $20 \%$, and (e) $25 \%$. 
Figures 6(a) and 6(b) show the relatively wide wear tracks, while Fig. 6(c) shows a significantly narrow wear track. It was reasonable to speculate that the $15 \%$ duty cycles with more $\mathrm{sp}^{3}$ bonding and a stable DLC structure resulted in the good adhesion strength and wear resistance. In addition, Fig. $6(d)$ shows a narrow and deep wear track. Moreover, the specimen of the $25 \%$ duty cycles generated a little spalling phenomenon between the DLC/oxynitrided films and the SKD11 substrate and displayed a wide and deep wear track, as shown in Fig. 6(e).

Figure 7 shows the SEM surface morphology of the wear test under a load of $5 \mathrm{~N}$ and a sliding speed of $0.25 \mathrm{~m} \cdot \mathrm{s}^{-1}$ by the different duty cycles of the bipolar-pulsed PECVD. Notably, Figs. 7(a) and 7(b) show a severe spalling phenomenon between the DLC/oxynitrided films and the SKD11 substrate. The DLC films also generated micro-cracks which extended outward, which caused a large area of spalling on the coating. The $5 \%$ and $10 \%$ duty cycles of the bipolarpulsed PECVD showed poor wear resistance under a high load and high sliding speed in the wear tests. The EDS composition analysis of Figs. 7(a) and 7(b) is listed in Table 1. Significantly, the compositions of positions 1 and 3 had a higher W element content (Figs. 7(a) and 7(b)), which showed the obvious wear tracks. Positions 2 and 4 had no
W elements; their main composition included $\mathrm{C}, \mathrm{Cr}$ and $\mathrm{Fe}$ elements. They also possessed higher contents of $\mathrm{O}$ and $\mathrm{N}$ elements. It was judged that the areas of positions 2 and 4 still retained DLC film and oxynitriding layers. In addition, the $15 \%$ duty cycles showed quite shallow wear tracks and little spalling phenomenon between the DLC/oxynitriding films and the SKD11 substrate (Fig. 7(c)). The 20 and 25\% duty cycles revealed more deep wear tracks and a uniform abrasive mechanism, as shown in Figs. 7(d) and 7(e). Our previous study ${ }^{3}$ indicated that the higher plasma energy easily caused the collision to be more intense under the plasma atmosphere, so that the DLC structure had a low content of both $\mathrm{sp}^{3}$ carbon and hydrogen. It was reasonable to speculate that when the duty cycles were increased to $20 \%$ and

Table 1. EDS composition (at.\%) analysis of wear specimens at four different spots as indicated in Figs. 7(a) and 7(b).

\begin{tabular}{cccccccc}
\hline & $\mathrm{C}$ & $\mathrm{O}$ & $\mathrm{Cr}$ & $\mathrm{Fe}$ & $\mathrm{W}$ & $\mathrm{Si}$ & $\mathrm{N}$ \\
\hline Position 1 & 14.06 & 58.13 & 2.38 & 23.00 & 2.43 & - & - \\
Position 2 & 26.21 & 17.59 & 3.72 & 31.94 & - & 1.45 & 19.09 \\
Position 3 & 30.75 & 49.87 & 1.85 & 14.86 & 1.51 & 1.16 & - \\
Position 4 & 31.18 & 10.11 & 17.33 & 12.60 & - & - & 28.78 \\
\hline
\end{tabular}
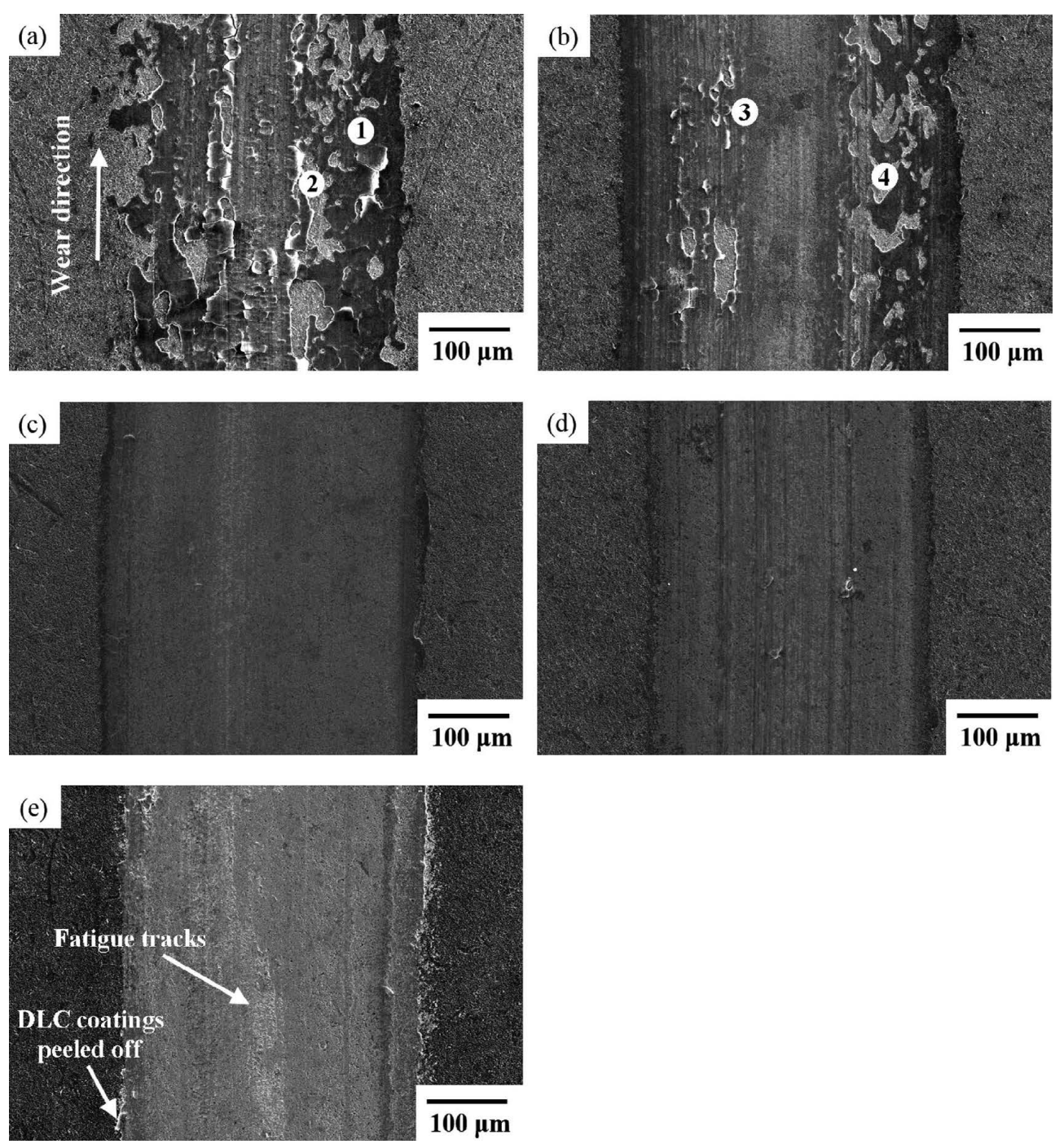

Fig. 7. Surface morphology of wear test (sliding speed $0.25 \mathrm{~m} \cdot \mathrm{s}^{-1}$ and load $5 \mathrm{~N}$ ) by the different duty cycles of bipolarpulsed PECVD: (a) $5 \%$, (b) $10 \%$, (c) $15 \%$, (d) $20 \%$, and (e) $25 \%$. 
$25 \%$, the $\mathrm{sp}^{3}$ easily transformed to $\mathrm{sp}^{2}$, which formed an unstable DLC structure. The DLC coating peeled off and fatigue tracks obviously appeared in the $25 \%$ duty cycles of the bipolar-pulsed PECVD. At the same time, the wear tests

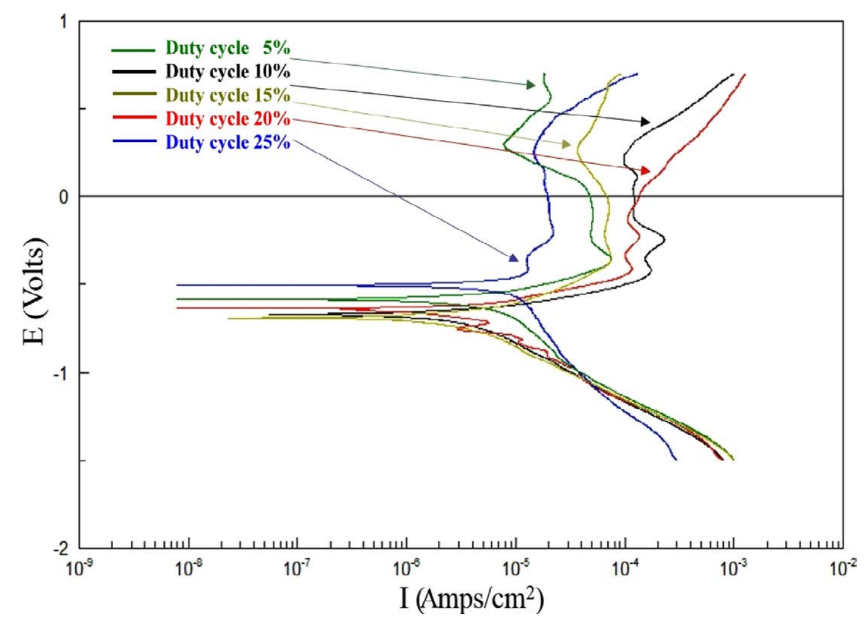

Fig. 8. Tafel results of SKD11 specimens by various duty cycles of bipolar-pulsed PECVD after 3.5 wt.\% $\mathrm{NaCl}$ corrosion test. (Online version in color.)
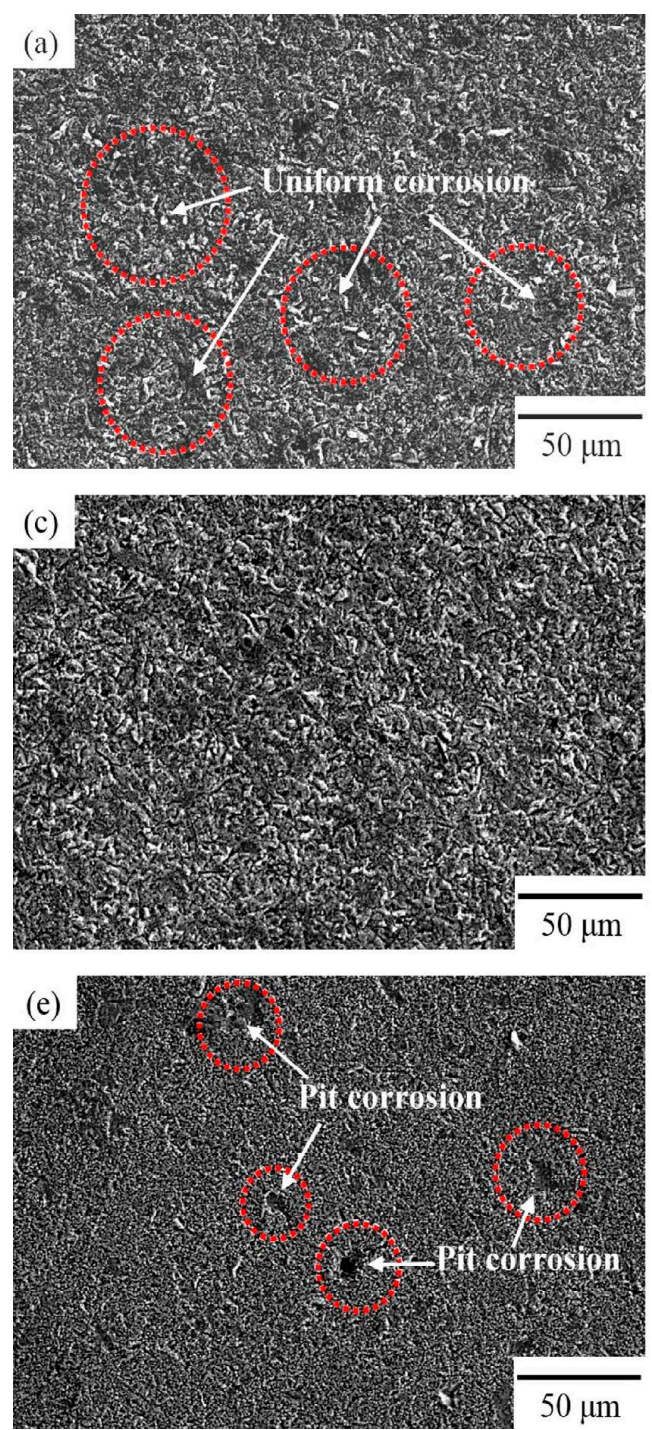

produced more obvious cracks and a spalling phenomenon, as shown in Fig. 7(e). Thus, the specimens of the 15\% duty cycles possessed the best wear resistance.

Figure 8 shows the Tafel slope results of the SKD11 specimens for the various duty cycles of bipolar-pulsed PECVD after the $3.5 \mathrm{wt} \% \mathrm{NaCl}$ corrosion test. All the different duty cycles of the bipolar-pulsed PECVD possessed a significant passivation phenomenon after the $3.5 \mathrm{wt} \% \mathrm{NaCl}$ corrosion test. The passivation effect of the various duty cycles of the bipolar-pulsed process was more obvious than that of the unipolar-pulsed voltage of the PECVD. ${ }^{3)}$ Since

Table 2. Comparison of the corrosion resistance of SKD11 specimens by various duty cycles of bipolar-pulsed PECVD after $3.5 \mathrm{wt} . \% \mathrm{NaCl}$ corrosion test.

\begin{tabular}{cccc}
\hline Specimens & $\mathrm{I}_{\text {corr }}\left(\times 10^{-6} \mathrm{~A} \cdot \mathrm{cm}^{-2}\right)$ & $\mathrm{E}_{\text {corr }}($ Volts $)$ & $\mathrm{R}_{\mathrm{p}}\left(\times 10^{3} \Omega \cdot \mathrm{cm}^{2}\right)$ \\
\hline $5 \%$ & 5.01 & -0.87 & 8.36 \\
$10 \%$ & 3.04 & -0.78 & 11.1 \\
$15 \%$ & 2.66 & -0.70 & 15.8 \\
$20 \%$ & 3.52 & -0.75 & 7.38 \\
$25 \%$ & 5.57 & -0.89 & 4.67 \\
\hline
\end{tabular}
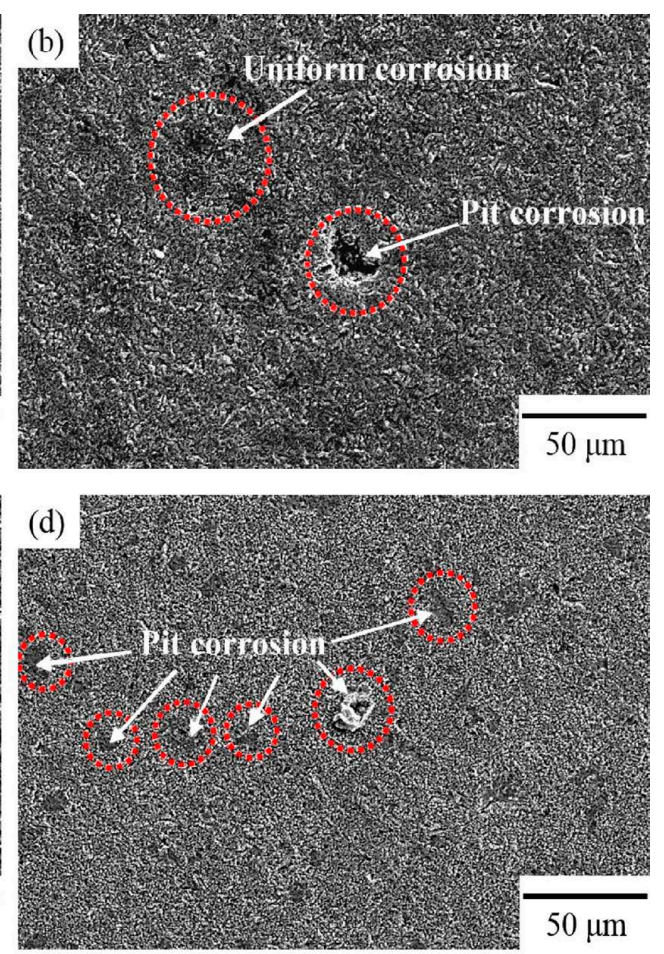

Fig. 9. SEM observations of SKD11 specimens by various duty cycles of bipolar-pulsed PECVD after $3.5 \mathrm{wt} . \% \mathrm{NaCl}$ corrosion test: (a) $5 \%$, (b) $10 \%$, (c) $15 \%$, (d) $20 \%$, and (e) $25 \%$. (Online version in color.) 
the passivation layer possessed a protective effect, it was shown that the bipolar-pulsed PECVD had the better corrosion resistance. A comparison of the corrosion resistance of the different duty cycles of the DLC/oxynitriding-treated SKD11 specimens is listed in Table 2.

From the view point of corrosion behavior, the samples with a lower current density $\left(\mathrm{I}_{\text {corr }}\right)$ and higher potential $\left(\mathrm{E}_{\text {corr }}\right.$ or polarization resistance $R_{p}$ ) evidenced better corrosion resistance. ${ }^{16)}$ Table 2 lists the corrosion resistance $\left(\mathrm{I}_{\text {corr }}, \mathrm{E}_{\text {corr }}\right.$ and $R_{p}$ ) of the different duty cycles of the DLC/oxynitriding-treated SKD11 specimens. The lowest corrosion current $\left(2.66 \times 10^{-6} \mathrm{~A} \cdot \mathrm{cm}^{-2}\right)$ and highest polarization resistance $\left(1.58 \times 10^{4} \Omega \cdot \mathrm{cm}^{2}\right)$ of the SKD11 specimens appeared in the $15 \%$ duty cycles of the bipolar-pulsed PECVD procedure. Our previous studies ${ }^{3,5)}$ indicated that the oxidationtreated steel usually formed a passive film (normally $\mathrm{Fe}_{3} \mathrm{O}_{4}$ structures), which contributed to a better anti-corrosion property during the corrosion test. Although the DLC films possessed excellent chemical inertness, the $\mathrm{sp}^{2}$ bonding generally accelerated the electromigration between the substrate and etching solutions, which resulted in increased current density and reduced corrosion resistance. Only with stable $\mathrm{sp}^{3}$ and $\mathrm{sp}^{2}$ bonding structures could good corrosion resistance be produced. Thus, the stable DLC structure and oxide layers of the DLC/oxynitriding-treated films were essential to improving corrosion resistance.

Figure 9 shows the SEM images of SKD11 specimens by the various duty cycles of the bipolar-pulsed PECVD after the corrosion tests. It was found that severe and uniform corrosion appeared in the specimen of the $5 \%$ duty cycle, as shown in Fig. 9(a). As the duty cycles of the bipolar-pulsed PECVD increased, the $\mathrm{sp}^{3}$ bonding structure of DLC stabilized and resulted in improved corrosion resistance. Minor uniform and pit corrosion appeared in the $10 \%$ duty cycle specimen, as shown in Fig. 9(b), while there was almost no significant corrosion in the $15 \%$ duty cycle specimen, as shown in Fig. 9(c). However, the higher plasma energy of the $20 \%$ and $25 \%$ duty cycles easily transformed the $\mathrm{sp}^{3}$ to $\mathrm{sp}^{2}$ bonding, which led to an unstable DLC structure and a significant decrease in corrosion resistance. More pit corrosion appeared in the $20 \%$ and $25 \%$ duty cycle specimens, as shown in Figs. 9(d) and 9(e). Consequently, the specimen of the $15 \%$ duty cycle of the bipolar-pulsed PECVD possessed the optimal corrosion resistance in a $3.5 \mathrm{wt} \% \mathrm{NaCl}$ solution.

\section{Conclusions}

The experimental results showed that a $20 \mu \mathrm{m}$ oxynitride layer and 1-2 $\mu \mathrm{m}$ of DLC thin films could be successfully obtained after JIS SKD11 steel was treated by the DLC/ oxynitriding duplex treatment. In this study, the optimal duty cycles of the bipolar-pulsed PECVD for coating DLC/ oxynitriding films onto JIS SKD11 steel was $15 \%$. The lower duty cycles $(5 \%$ and $10 \%)$ had more off-time sufficient to release the charge accumulation; thus, the gas dissociation rate was relatively lower, which resulted in the poor properties of the DLC films. Conversely, the higher duty cycles $(20 \%$ and $25 \%)$ with a longer period of plasma bombardment, easily led to a greater internal residual stress and more uneven $\mathrm{sp}^{3}$ and $\mathrm{sp}^{2}$ structures.

In addition, the lowest corrosion current $\left(2.66 \times 10^{-6}\right.$ $\left.\mathrm{A} \cdot \mathrm{cm}^{-2}\right)$ and highest polarization resistance $\left(1.58 \times 10^{4}\right.$ $\Omega \cdot \mathrm{cm}^{2}$ ) appeared in the specimen of the $15 \%$ duty cycle. When the duty cycle $(15 \rightarrow 20 \rightarrow 25 \%)$ of the bipolarpulsed PECVD process was increased, the ion energy of the plasma bombardment was too high and resulted in the rapid increase in the specimen's surface energy. As a result, the $\mathrm{sp}^{3}$ structure of the DLC films was transformed to $\mathrm{sp}^{2}$, thus decreasing their corrosion resistance. Significantly, the optimal DLC films effectively improved the tribological and corrosion properties of the DLC/oxynitriding-treated JIS SKD11 steel, as evidenced by the experiment using a $15 \%$ duty cycle of bipolar-pulsed PECVD technology.

\section{Acknowledgments}

The experimental equipments are supported by the Department of Chemical and Material Engineering Lunghwa University of Science and Technology, and ASSAB STEELS TAIWAN CO., LTD.

\section{REFERENCES}

1) A. Kagiyama, K. Terakadoa and R. Urao: Surf. Coat. Technol., 169-170 (2003), 397.

2) H. T. Lee, W. P. Rehbach, F. C. Hsu, T. Y. Tai and E. Hsu: J. Mater. Process. Technol., 149 (2004), 88.

3) S. H. Chang, C. I. Lee and K. T. Huang: ISIJ Int., 54 (2014), 193.

4) S. H. Chang, Y. K. Lin and K. T. Huang: Surf. Coat. Technol., 207 (2012), 571.

5) S. H. Chang, T. P. Tang, Y. C. Chen and J. K. Chen: ISIJ Int., 49 (2009), 421

6) X. D. Yang, T. Saito, Y. Nakamura, Y. Kondo and N. Ohtake: Diam. Relat. Mater., 13 (2004), 1984.

7) G. Fedosenko, A. Schwabedissen, J. Engemann, E. Braca, L. Valentini and J. M. Kenny: Diam. Relat. Mater., 11 (2002), 1047.

8) S. Ma, K. Xu and W. Jie: Surf. Coat. Technol., 191 (2005), 201.

9) T. Aizawa and T. Fukuda: Surf. Coat. Technol., 215 (2013), 364.

10) B. Halliop, M. F. Salaun, W. Favre, R. Varache, M. E. GueunierFarret, J. P. Kleider and N. P. Kherani: J. Non-Cryst. Solids., 358 (2012), 2227.

11) O. Kyrylov, R. Cremer and D. Neuschütz: Surf. Coat. Technol., 163-164 (2003), 203.

12) Ch. Täschner, B. Ljungberg, V. Alfredsson, I. Endler and A. Leonhardta: Surf. Coat. Technol., 108-109 (1998), 257.

13) N. Vidakis, A. Antoniadis and N. Bilalis: J. Mater. Process. Technol., 143-144 (2003), 481.

14) M. Umeno, M. Noda, H. Uchida and H. Takeuchi: Diam. Relat. Mater., 17 (2008), 684.

15) C. C. Chen and F. C. N. Hong: Appl. Surf. Sci., 243 (2005), 296.

16) F. R. Marciano, E. C. Almeida, D. A. Lima-Oliveira, E. J. Corat and V. J. Trava-Airoldi: Diam. Relat. Mater., 19 (2010), 537. 